\title{
MicroRNA expression profiling of carcinoma in situ cells of the testis
}

\author{
Guy Wayne Novotny ${ }^{\star}$, , Kirstine C Belling ${ }^{1 *}$, Jesper Bertram Bramsen ${ }^{2}$, \\ John E Nielsen, Jette Bork-Jensen ${ }^{3}$, Kristian Almstrup, Si Brask Sonne ${ }^{\ddagger}$, \\ Jørgen Kjems ${ }^{2}$, Ewa Rajpert-De Meyts and Henrik Leffers ${ }^{\ddagger}$
}

\author{
Department of Growth and Reproduction, Rigshospitalet, Blegdamsvej 9, 2100 Copenhagen, Denmark \\ ${ }^{1}$ Center for Biological Sequence Analysis, Institute for Systems Biology, Technical University of Denmark, Kemitorvet Building 208 , \\ 2800 Lyngby, Denmark \\ ${ }^{2}$ Department of Molecular Biology, Aarhus University, C.F. Møllers Allé, Aarhus C, Denmark \\ ${ }^{3}$ Steno Diabetes Center A/S, Niels Steensens Vej 2-4, 2820 Gentofte, Denmark \\ (Correspondence should be addressed to $\mathrm{H}$ Leffers who is now at Department of Biology, University of Copenhagen, The August \\ Krogh Building, Universitetsparken 13, DK-2100 Copenhagen, Denmark; Email: henrik.leffers@biobase.dk) \\ *(G W Novotny and K C Belling contributed equally to this work) \\ ${ }^{\dagger}$ (G W Novotny is now at Biomedical Institute, The Panum Institute, University of Copenhagen, Blegdamsvej 3B, Copenhagen, \\ Denmark) \\ ${ }^{\ddagger}$ (S B Sonne and H Leffers are now at Department of Biology, University of Copenhagen, The August Krogh Building, \\ Universitetsparken 13, DK-2100 Copenhagen, Denmark)
}

\begin{abstract}
Testicular germ cell tumours, seminoma (SE) and non-seminoma (NS), of young adult men develop from a precursor cell, carcinoma in situ (CIS), which resembles foetal gonocytes and retains embryonic pluripotency. We used microarrays to analyse microRNA (miRNA) expression in 12 human testis samples with CIS cells and compared it with miRNA expression profiles of normal adult testis, testis with Sertoli-cell-only that lacks germ cells, testis tumours (SE and embryonal carcinoma (EC), an undifferentiated component of NS) and foetal male and female gonads. Principal components analysis revealed distinct miRNA expression profiles characteristic for each of the different tissue types. We identified several miRNAs that were unique to testis with $\mathrm{CIS}$ cells, foetal gonads and testis tumours. These included miRNAs from the hsa-miR-371-373 and $-302-367$ clusters that have previously been reported in germ cell tumours and three miRNAs (hsa-miR-96, -141 and -200c) that were also expressed in human epididymis. We found several miRNAs that were upregulated in testis tumours: hsa-miR-9, -105 and $-182-183-96$ clusters were highly expressed in SE, while the hsa-miR-515-526 cluster was high in EC. We conclude that the miRNA expression profile changes during testis development and that the miRNA profile of adult testis with CIS cells shares characteristic similarities with the expression in foetal gonocytes.
\end{abstract}

Endocrine-Related Cancer (2012) 19 365-379

\section{Introduction}

Testicular germ cell tumours (TGCTs) are the most common malignancies of adolescents and young men, with the majority of cases occurring from ages 18 to 45 years (Winter \& Albers 2011). Testis cancers are treatable with a survival rate of $50-90 \%$ depending on tumour type and progression stage (Schmoll et al. 2004). However, testis cancer patients often have reduced fertility, and orchidectomy of the affected testicle and cisplatin treatment can result in a further reduction of their fertility. Survivors in addition suffer from a range of treatment effects, which significantly reduce later quality-of-life (Feldman et al. 2008).

TGCTs arise from precursor cells named carcinoma in situ (CIS), which are of foetal origin (Skakkebaek et al. 1987). The CIS cells persist quiescently in the testis until puberty where hormone signals initiate spermatogenesis. These signals apparently result in the proliferation of the CIS cells, which progress to overt tumours that are classified as either seminoma (SE) that generally does not differentiate or non-seminoma (NS), which has a striking ability to differentiate into 
virtually any type of tissue (Ulbright et al. 1999, Looijenga et al. 2007). The pluripotent nature of NS tumours is probably inherited from the CIS cells, as gene expression studies have shown a significant overlap of gene expression between CIS cells and embryonic stem cells (ESCs; Almstrup et al. 2004). Visually, CIS cells resemble foetal gonocytes (Holstein \& Korner 1974), and recent investigations of microdissected tissues have shown a close resemblance in gene expression between CIS cells and gonocytes (Sonne et al. 2009a). This strongly suggests that CIS cells arise from foetal gonocytes, which failed to differentiate to pre-spermatogonia, and instead survived as quiescent gonocyte-like cells in the testis.

Recently, it has become widely appreciated that much of a cell's biology and function can be regulated at the translational level through a class of small RNAs, microRNAs (miRNAs). Most miRNAs specifically inhibit translation of mRNAs through binding to complementary sequences in the $3^{\prime}$-UTR (Lai 2002, Bartel 2004, Xie et al. 2005), while some can enhance translation through binding to regulatory elements on the mRNA (Orom et al. 2008). In addition, binding of miRNAs usually also leads to a reduction of the level of their target mRNAs (Eulalio et al. 2009). Deregulation of miRNAs that regulate tumour suppressors or oncogenes often plays a role in cancer development (Esquela-Kerscher \& Slack 2006, Cho 2007). In the testis, the oncogenic miRNA clusters hsa-miR-372 and -373 contribute to cancer development by disabling the p53 pathway through lowering LATS2 protein levels (Voorhoeve et al. 2006), while another oncogenic miRNA cluster, hsa-miR-17-92 (He et al. 2005, O'Donnell et al. 2005), may promote the development of overt tumours through the prevention of apoptosis by inhibiting E2F1 protein synthesis in CIS cells (Novotny et al. 2007a). Additionally, recent quantitative reverse transcriptase-PCR (qRT-PCR) studies of miRNA expression in germ cell tumours have shown differential expression of several miRNAs between normal tissue and tumour samples (Gillis et al. 2007, Palmer et al. 2010). Taken together, these studies have indicated that miRNA regulation may play a role in the development of TGCTs; however, no data on miRNA expression in the CIS cell are currently available. Achieving this information is not trivial as the CIS cell is a rare cell type, comprising at most $5-10 \%$ of the cells in the testis, and the techniques applicable for purifying CIS cells through microdissection are not suitable for detecting miRNAs.

The aims of this study were to identify the miRNA expression profile in CIS cells and to investigate the role of individual miRNAs in tumour development and progression. For this purpose, we applied microarray technology to detect miRNAs expressed in CIS cells by comparing normal human testis samples with samples containing varying amounts of tubules with CIS. We also performed miRNA analysis of a series of TGCTs (SE and embryonal carcinoma (EC), which is the pluripotent undifferentiated component of NS) and of male and female foetal gonads. Combining the miRNA expression data with data on mRNA expression in microdissected testicular tissues and CIS cells allowed us to perform a bioinformatics investigation to predict putative targets for the miRNAs expressed in CIS cells. Finally, we looked into the function of the predicted targets by gene set enrichment analysis to gain further knowledge of the role of the miRNAs and their targets in CIS cell biology.

\section{Materials and methods}

\section{Tissue samples and RNA preparation}

Use of adult testicular tissues was approved by the Regional Committee for Medical Research Ethics in Denmark. The samples were obtained from the residual tissue of the orchidectomy specimens from patients diagnosed with malignant testicular cancer. Normal samples were obtained from areas with preserved complete spermatogenesis, where no tumour or CIS cells were present, or purchased commercially Applied Biosystems/Ambion, Foster City, CA, USA and Biochain Institute, Newark, CA, USA). The tissue samples were either snapfrozen at $-80{ }^{\circ} \mathrm{C}$ or fixed overnight at $4{ }^{\circ} \mathrm{C}$ in Stieve's fluid or paraformaldehyde, and subsequently embedded in paraffin. The samples were stained with haematoxylin-eosin for histological evaluation and with an antibody against placental alkaline phosphatase to confirm the presence of CIS, as described previously (Giwercman et al. 1991). Foetal gonads were collected in the UK according to the Polkinghorne guidelines following ethical approval and informed consent of women who underwent elective abortions at 10-12 weeks of pregnancy as described previously (Sonne et al. 2009a). Three foetal gonadal samples were available for this study: two male (of which one contained testis and mesonephros tissue and the other only mesonephros) and one female (containing ovary and mesonephros tissue; Table 1). The foetal gonads were embedded in 'optimum cutting temperature compound' (Sakura Fintek Europe, Alphen aan den Rijn, The Netherlands) and snap-frozen at $-80{ }^{\circ} \mathrm{C}$. Total RNA was 
Table 1 Tissue and RNAs used in this study

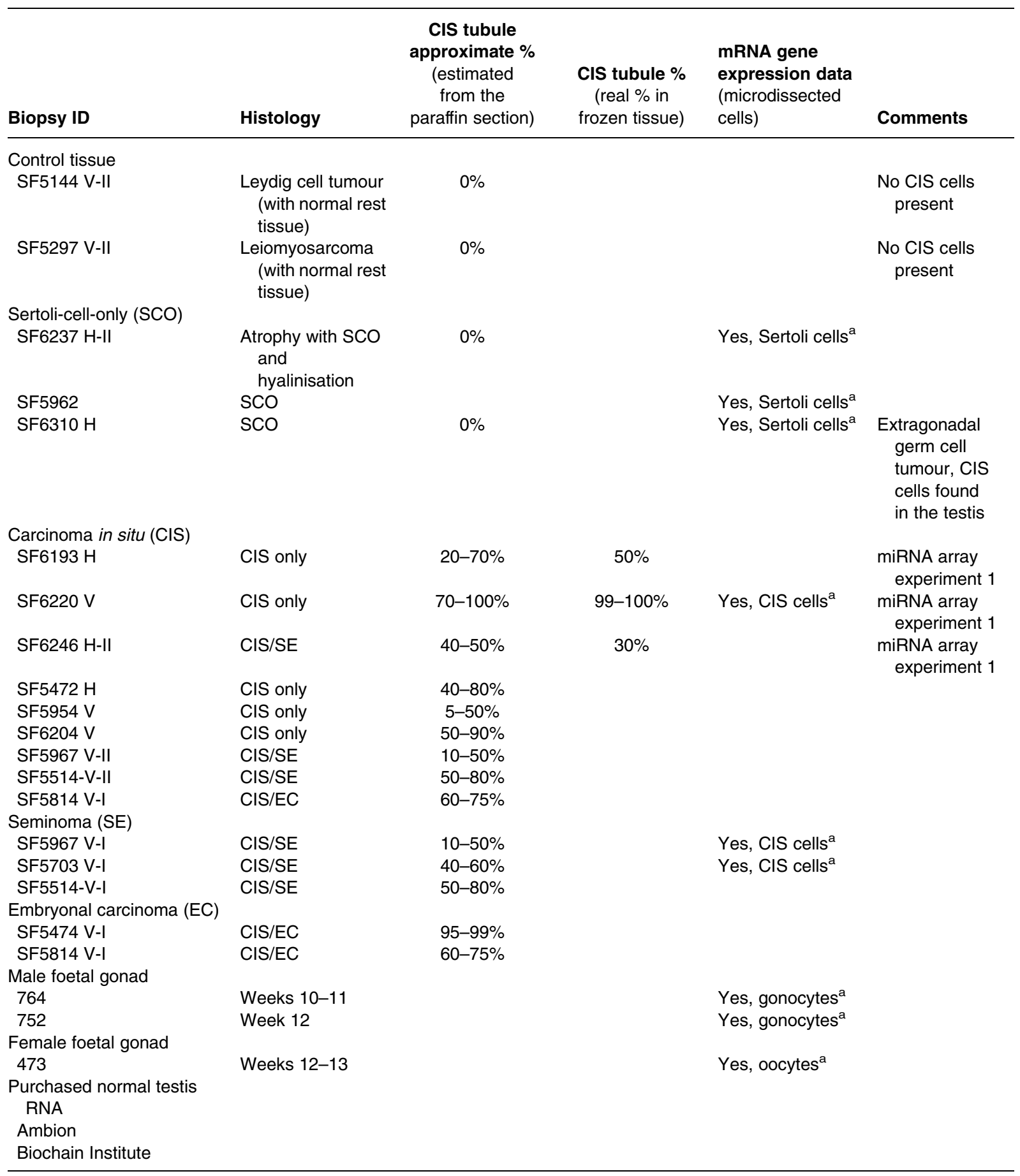

aSonne et al. (2009a).

prepared from minor amounts of the frozen tissue samples (adult testis) or from serial sections of the tissue (foetal gonads) using Trizol reagent (Invitrogen, Carlsbad, CA, USA) according to the manufacturer's protocol.

\section{miRNA array analysis and qRT-PCR expression profiling}

The Agilent (Agilent Technologies, Santa Clara, CA, USA) Human miRNA microarray v1.0 (four samples: three CIS and one normal adult testis) and the Agilent 
Human miRNA microarray v2.0 (24 samples: nine CIS, four normal adult testis, three Sertoli-cell-only (SCO), two EC, three SE and three foetal samples) were used for profiling the miRNA expression (Table 1). One hundred nanograms of the total RNA from each sample were labelled and hybridised to the arrays following the manufacturer's instructions. Array images were scanned using an Agilent scanner G2565BA with scanner software version A. 7.0.1 with XDR function, and data obtained using Agilent Feature Extraction Software version 9.5.3.1. The per-array lowessnormalised signal (gProcessedSignal) from each array was normalised to each other by quantile normalisation using the marray package in $\mathrm{R} / \mathrm{bioC}$ version 2.7 .2 (www.bioconductor.org/). Statistical analysis (hierarchical clustering and significance analysis of microarrays (SAM)) of the normalised data was performed using TIGR MeV v4.0 (The Institute for Genomics Research, La Jolla, CA, USA) (Saeed et al. 2003), while principal components analysis (PCA) was performed using $\mathrm{R} / \mathrm{bioC}$ version 2.7.2. The miRNA array data have been submitted to the Gene Expression Omnibus (http:// www.ncbi.nlm.nih.gov/geo/) and have been assigned the accession number GSE31824.

For the verification of the microarray results, we performed the qRT-PCR validation of nine miRNAs using TaqMan miRNA assays (Applied Biosystems) as described by the supplier; hsa-miR-103 was used for normalisation.

\section{In situ hybridisation}

In situ hybridisation (ISH) probes for pri-hsa-miR-96 and pri-hsa-miR-371 were prepared using two sets of specific primers for each. The first set (to amplify the cDNA) was for pri-hsa-miR-96: AGAGTGTGACTCCTGTTCTGT and TTGGCACTGCACATGATTGCT; and for pri-hsamiR-371: GATCGCCGCCTTGCCGCA and TCGTGATGCCCTACTCAAACA. One microlitre from the first PCR sample was used for the second amplification (for adding T3 or T7 promoters respectively (underlined)): for pri-hsa-miR-96 - AATTAACCCTCACTAAAGGGTATGGCACTGGTAG and TAATACGACTCACTATAGGGCAGAGCGGAGAGA; and for prihsa-miR-371-AATTAACCCTCACTAAAGGGCACTCAAACTGT and TAATACGACTCACTATAGGGTGACGCTCAAAT. PCR amplification for the first set was as follows: $95^{\circ} \mathrm{C}$ for $5 \mathrm{~min}, 35$ cycles of $95^{\circ} \mathrm{C}$ for $30 \mathrm{~s}, 62{ }^{\circ} \mathrm{C}$ for $1 \mathrm{~min}$ and $72{ }^{\circ} \mathrm{C}$ for $1 \mathrm{~min}$, followed by $5 \mathrm{~min}$ at $72{ }^{\circ} \mathrm{C}$. PCR for the second set was as follows: $95^{\circ} \mathrm{C}$ for $5 \mathrm{~min}$, followed by five cycles of $95^{\circ} \mathrm{C}$ for $30 \mathrm{~s}$, $45^{\circ} \mathrm{C}$ for $1 \mathrm{~min}$ and $72^{\circ} \mathrm{C}$ for $1 \mathrm{~min}$, followed by 20 cycles of $95^{\circ} \mathrm{C}$ for $30 \mathrm{~s}, 65^{\circ} \mathrm{C}$ for $1 \mathrm{~min}$ and $72{ }^{\circ} \mathrm{C}$ for
1 min. After a final 5 min extension step at $72{ }^{\circ} \mathrm{C}$, the reaction was stopped. The PCR product was purified on an agarose gel and sequenced. Aliquots of $200 \mathrm{ng}$ were used for in vitro transcription labelling of the RNA probes using MEGAscript-T3 (sense) or MEGAscript-T7 (antisense) following the manufacturer's protocol (Ambion, Applied Biosystems). ISH was performed as described previously (Nielsen et al. 2003, Novotny et al. 2007b).

\section{miRNA target prediction and enrichment analysis}

miRNA targets were predicted for the 13 miRNAs from the first miRNA study (Table 2), as well as for hsa-miR-141, -183, -200c and -323-3p using miRecords (http://mirecords.biolead.org/), an integrated database of 11 prediction algorithms. Our criterion for the target prediction was that each target was predicted by at least six of the 11 prediction algorithms. Gene set enrichment analysis of the miRNA targets was performed using the Panther Classification System (http://www.pantherdb.org/ tools/compareToRefListForm.jsp). As a reference, we used all the identifiers on the array.

\section{Microarray analysis of mRNA expression}

Microarray data from three samples of microdissected CIS cells, three samples of microdissected Sertoli cells, two samples of microdissected gonocytes, one microdissected oocyte sample and three samples of total RNA from the normal testis were available from a previous study (Table 1; Sonne et al. 2009a). The microarray images were read by Agilent Feature Extraction Software version 9.5.3.1 and analysed in the R/BioC limma package using the gMedianSignals. Normalisation between the arrays was done using a quantile normalisation procedure and probes were collapsed by taking the median. CIS vs normal testis samples was statistically tested by an unpaired $t$-test and $P$ values were corrected for multiple testing by Benjamini-Hochberg correction.

\section{Results}

\section{miRNA microarray results}

To identify the miRNAs expressed in CIS cells, we performed an initial array experiment using RNA from the normal testis and from three testis biopsies containing variable amounts of CIS cells. In this manner, we could determine CIS-enriched miRNAs by correlating miRNA expression with the CIS cell content, as we previously have done with mRNAs 
Table 2 Expression of miRNAs correlated with the percentage of carcinoma in situ (CIS) tubules

\begin{tabular}{|c|c|c|c|c|c|c|c|}
\hline miRNA & Normal & CIS30 & CIS50 & CIS100 & $\begin{array}{c}\text { Pearson's } \\
\text { correlation } \\
\text { coefficient }(R)\end{array}$ & $\begin{array}{l}\text { Upregulated in } \\
\text { stem cell/cancer }\end{array}$ & Reference \\
\hline hsa-miR-367 & 3 & 85 & 236 & 395 & 0.987 & iPSC, hESC, cancer & $\begin{array}{l}\text { Gillis et al. (2007) and } \\
\text { Wilson et al. (2009) }\end{array}$ \\
\hline hsa-miR-371 & 0 & 253 & 969 & 1917 & 0.983 & hESC, cancer & $\begin{array}{l}\text { Voorhoeve et al. (2006) } \\
\text { and Wilson et al. (2009) }\end{array}$ \\
\hline hsa-miR-373 & 8 & 510 & 1917 & 3520 & 0.982 & hESC, cancer & $\begin{array}{l}\text { Voorhoeve et al. (2006) } \\
\text { and Wilson et al. (2009) }\end{array}$ \\
\hline hsa-miR-96 & 1 & 6 & 18 & 47 & 0.978 & hESC, cancer & $\begin{array}{l}\text { Wilson et al. (2009) and } \\
\text { Yamada et al. (2011) }\end{array}$ \\
\hline $\begin{array}{l}\text { hsa-miR- } \\
302 b^{*}\end{array}$ & -2 & -1 & 4 & 12 & 0.975 & iPSC, hESC, cancer & $\begin{array}{l}\text { Gillis et al. (2007) and } \\
\text { Wilson et al. (2009) }\end{array}$ \\
\hline hsa-miR-183 & 1 & 4 & 17 & 37 & 0.972 & Cancer & $\begin{array}{c}\text { Gillis et al. (2007) and } \\
\text { Sarver et al. (2010) }\end{array}$ \\
\hline hsa-miR-302b & -1 & 26 & 88 & 128 & 0.967 & iPSC, hESC, cancer & $\begin{array}{l}\text { Gillis et al. (2007) and } \\
\text { Wilson et al. (2009) }\end{array}$ \\
\hline hsa-miR-302d & -1 & 28 & 113 & 168 & 0.963 & iPSC, hESC, cancer & $\begin{array}{l}\text { Gillis et al. (2007) and } \\
\text { Wilson et al. (2009) }\end{array}$ \\
\hline $\begin{array}{l}\text { hsa-miR- } \\
\text { 302a* }\end{array}$ & -1 & 30 & 94 & 130 & 0.96 & iPSC, hESC, cancer & $\begin{array}{l}\text { Gillis et al. (2007) and } \\
\text { Wilson et al. (2009) }\end{array}$ \\
\hline hsa-miR-302a & -1 & 45 & 152 & 203 & 0.953 & iPSC, hESC, cancer & $\begin{array}{l}\text { Gillis et al. (2007) and } \\
\text { Wilson et al. (2009) }\end{array}$ \\
\hline hsa-miR-372 & 10 & 801 & 3656 & 5095 & 0.95 & hESC, cancer & $\begin{array}{l}\text { Voorhoeve et al. (2006) } \\
\text { and Wilson et al. (2009) }\end{array}$ \\
\hline hsa-miR-302c & -1 & 4 & 26 & 34 & 0.933 & iPSC, hESC, cancer & $\begin{array}{l}\text { Gillis et al. (2007) and } \\
\text { Wilson et al. (2009) }\end{array}$ \\
\hline
\end{tabular}

(Almstrup et al. 2004). To visualise and quantify the CIS cell content prior to purifying RNA from the tissue, we applied a fast NBT-BCIP staining protocol (Sonne et al. 2009b). We estimated that samples 1-3 contained CIS cells in 30, 50 and $99-100 \%$ of the tubules respectively (Table 1 and data not shown). We then performed miRNA expression profiling on the Agilent Human miRNA microarray v1.0 platform (containing probes for 470 human miRNAs and 64 human viral miRNAs). The expression levels were correlated with the CIS cell content and the miRNAs with the highest correlations and with no or very low expression in the normal testis are shown in Table 2 (for a complete list of correlations, see Supplementary Table 1, see section on supplementary data given at the end of this article). The miRNAs that displayed increasing expression with increasing CIS content and low expression in the normal testis were miRNAs previously reported in stem cells and cancer (Table 2).

Following the initial experiments, we expanded our investigation by applying the Agilent Human miRNA microarray v2.0 (containing probes for 723 human miRNAs and 76 human viral miRNAs) to profile the miRNA expression of 24 human tissue samples (Table 1) divided between the normal testis $(n=4)$, testis with CIS cells $(n=9)$, non-cancerous biopsies of
SCO testis, which lack germ cells $(n=3)$, TGCTs (SE, $n=3$ and EC, $n=2)$ and foetal gonads $(n=3$; Table 1$)$. Unsupervised hierarchical clustering (UHC) resulted in overlapping but distinct clustering of the different testis tissue subtypes (Fig. 1a), indicating the presence of unique miRNA signatures in each respective tissue group. PCA (Fig. 1b) also revealed discrete groupings of the tumour types (EC and SE) and the foetal gonads, while the samples consisting of the normal testis, SCO and CIS formed a large group. The grouping of CIS with non-cancerous adult testes was expected, because at least $90 \%$ of the cells in the CIS samples were normal testicular cells (mainly somatic cells). Several of the samples were paired, where the samples of the tumour and the adjacent testis tissue with CIS originated from the same patient (Fig. 1a and b, compare patient numbers). Although originating from an identical genetic background, the miRNA signatures between the tissue containing CIS and the corresponding tumour were sufficiently different to allow sorting according to tissue type rather than by patient in the UHC and PCA plots.

High expression levels of the testis/gonadal-specific miRNA hsa-miR-202 (Landgraf et al. 2007, Ro et al. 2007) were seen in all testicular samples, while the tumours showed varying levels of expression (Fig. 1c). 
Of the foetal samples, the foetal gonad male_2 had a very low level of hsa-miR-202, indicating that it mainly consisted of tissue from the mesonephros (an embryonic kidney-like organ that eventually develops into the epididymis and seminal vesicles).
Immunohistochemistry with anti-Müllerian hormone $(\mathrm{AMH})$ confirmed that the sample was of male origin (data not shown). The embryonic hsa-miR-17-92 cluster was highly expressed in the foetal gonadal samples, indicating their embryonic origin (Fig. 1c). (a)

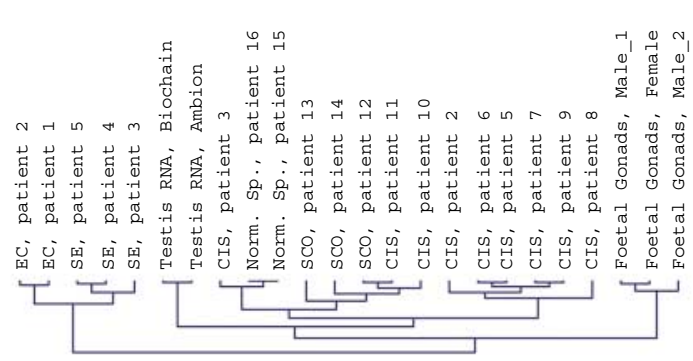

Unsupervised hierarchical clustering

(b)

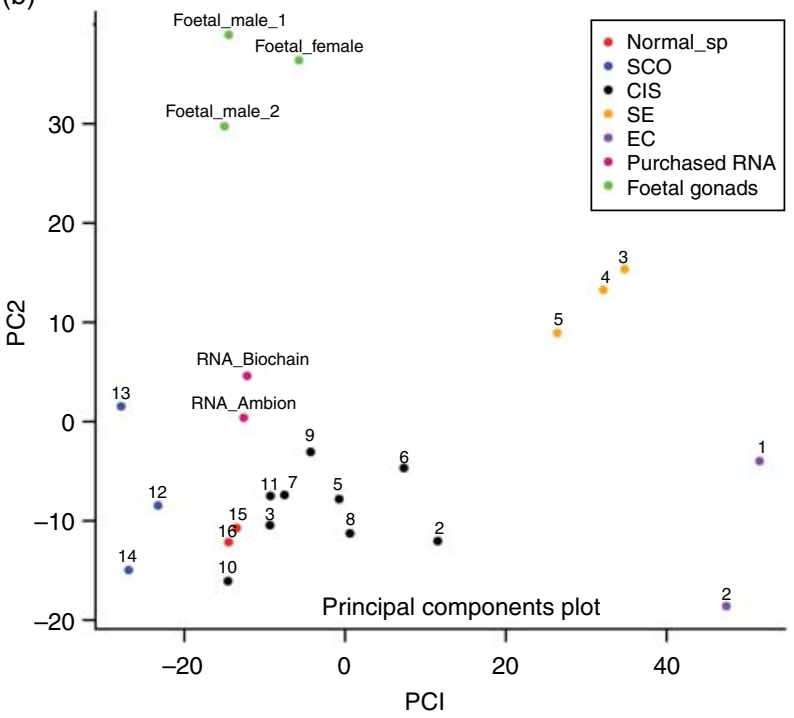

(c)
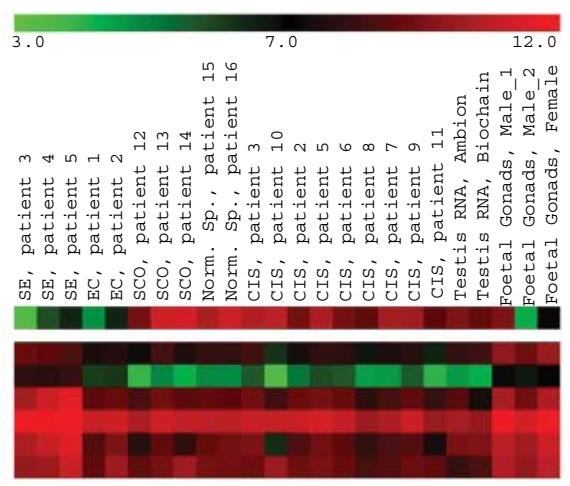

(d)
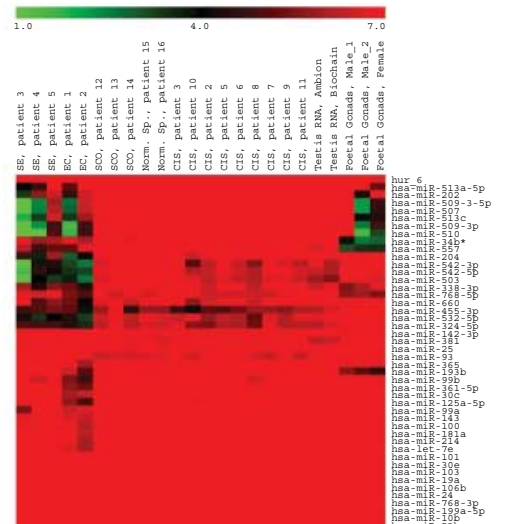

ha-miR-202

hsa-miR-17

hsa-miR-18a hsa-miR-19a hsa-miR-19b hsa-miR-20a hsa-miR-92a

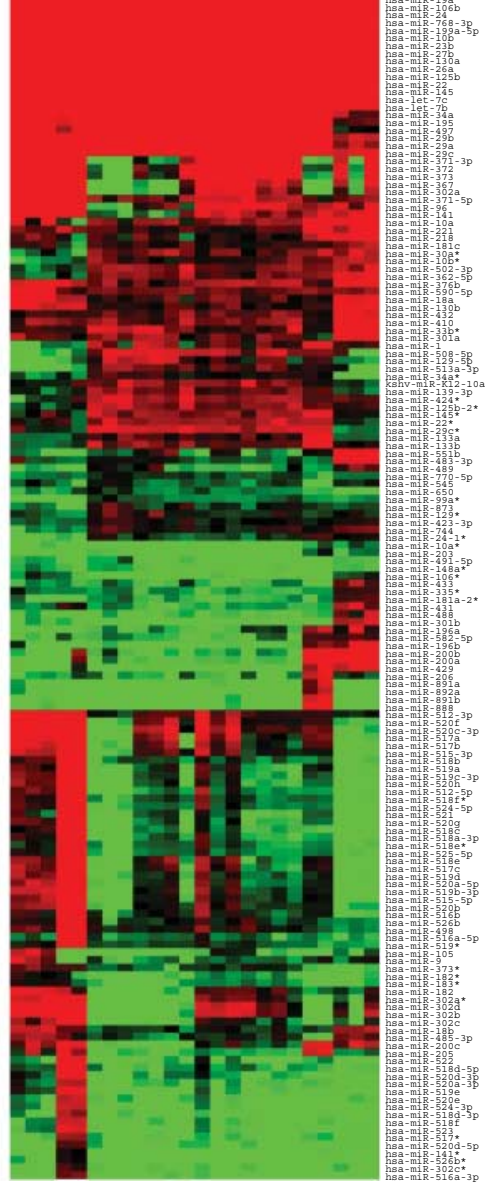

Figure 1 Visualisation of the miRNA microarray data. (a) Unsupervised hierarchical clustering of all samples based on the expression of all probes: EC, embryonal carcinoma; SE, seminoma; CIS, testis sample with carcinoma in situ (CIS); Norm. Sp, sample with normal spermatogenesis; SCO, Sertoli-cell-only (testis sample with no germ cells). (b) Principal components analysis based on all expression data from all the samples. Numbers correspond to the patient identifiers. (c) $\log _{2}$-fold heat map of the gonadal miRNA hsa-miR-202 and the embryonal miRNA cluster hsa-miR-17-92. (d) Log $_{2}$-fold heat map of all differentially expressed miRNAs in the seven-way SAM analysis ( $\delta 0.288$; FDR $0.0 \%$ ). 


\section{miRNAs differentiating between tissue subtypes}

To find miRNAs differentially expressed between the tissue samples, we performed a multifactorial SAM analysis among the seven distinct tissue groups (group 1, samples with normal spermatogenesis; group 2, SCO; group 3, CIS; group 4, SE; group 5, EC; group 6, purchased normal testis RNA; group 7, foetal gonads), resulting in a list of 193 miRNAs (Fig. 1d). The multifactorial SAM analysis revealed a group of testis-specific miRNAs (hsa-miR-506-510, $-513 \mathrm{abc}$ and -514 ; Bentwich et al. 2005) that were highly expressed in all adult testis samples (Fig. 2a). Interestingly, the foetal gonad male_1 sample (gestational weeks 10-11) had a high expression of the miRNAs, while the female foetal gonad (gestational weeks 13-14) showed very low expression, indicating that these miRNAs may have a very early role in testis development. In accordance with the testis specificity of this cluster, the foetal gonad male_2 sample, consisting of the mesonephros, showed no expression of these miRNAs and the SE and EC samples showed greatly reduced levels, suggesting that the miRNAs are expressed in somatic cells, which is supported by their presence in SCO. The SAM analysis also revealed several miRNAs that were present at much higher levels in the commercial testis RNA samples than in the normal testis samples from patients (Supplementary Figure 1a, see section on supplementary data given at the end of this article). Based on the miRNA expression atlas (Landgraf et al. 2007), it was evident that these miRNAs are expressed in the epididymis and not in the normal testis, suggesting that the commercial 'testis RNA' included RNA from both testis and epididymis (Supplementary Figure 1b, see section on supplementary data given at the end of this article).

To identify miRNAs important for the development of CIS, we made a heat map of the data from the 24 human samples from the list of miRNAs that correlated with the percentage of CIS tubules (Supplementary Table 1, see section on supplementary data given at the end of this article; Fig. 2b) and also performed a SAM analysis between the CIS samples and the adult non-malignant testis samples (normal spermatogenesis + SCO). We observed a very consistent co-expression of almost all the miRNAs in the samples with CIS cells and foetal gonads, where 50 of the 55 miRNAs, shown in Fig. 2b, also were expressed in the foetal samples. Moreover, all the miRNAs we found in the SAM analysis were already in the list of miRNAs that correlated with the percentage of tubules with CIS (Supplementary Table 1, see section on supplementary data given at the end of this article and results not shown). The miRNAs enriched in the CIS samples included the hsa-miR-371-373 and -302-367 clusters, which were low expressed or absent from the normal testis and the epididymal hsa-miR-182, -183 and $-200 \mathrm{c}$.

To gain insight into how the CIS cells progress into overt tumours, we performed SAM analysis between the CIS samples and the SE and EC tumours (Fig. 2c and $d$ respectively). There were differences in the expression in SE and EC: the hsa-miR-9 and -105 clusters were high in SE; the hsa-miR-182-183-96 cluster was high in SE and EC (Fig. 2b, c and d). We further investigated the differences between the CIS samples and foetal gonads in the SAM analysis (Fig. 2e). We found 38 miRNAs that were higher in foetal gonads than in CIS (results not shown); however the upregulated miRNAs were also expressed in the mesonephros sample, indicating that these miRNAs did not originate from gonocytes. Similarly for most miRNAs with low expression in the foetal samples, their low expression compared with the CIS samples can be attributed to the presence of the normal testis tissue in the CIS samples. The most intriguing observation was a cluster of miRNAs (hsa-miR-515526) that was not expressed in the foetal samples, expressed in the samples with CIS and in SE and highly expressed in EC (Fig. 2d and e).

\section{Validation of the array results}

We selected eight miRNAs (hsa-miR-105, -141, -200c, $-34 c-5 p,-367,-371-3 p,-520 c-3 p$ and -96$)$ for verification of the array data by qRT-PCR analysis. There was a strong correlation between the miRNA expression detected by the microarrays and the qRTPCR results (Fig. 3a and b and results not shown). We performed ISH experiments to assign expression of the selected miRNA precursors to the distinct cell types. We detected the pri-hsa-miR-182-183-96 cluster transcript in the nuclei of the CIS cells (Fig. 3c), while we were unable to detect transcripts of the hsa-miR-302-367 and -371-373 clusters, presumably because of scarce amounts of the precursor due to fast processing to the mature miRNA forms. For the hsa-miR-371-373 cluster, ISH detected cytoplasmic transcripts from the opposite strand (Fig. 3d), which is in accordance with data from Ensembl (ensembl.org) that show that several transcripts (DB443882, AI825624 and AW833903) from the opposite strand are expressed in testis and testis cancers. 
(a)

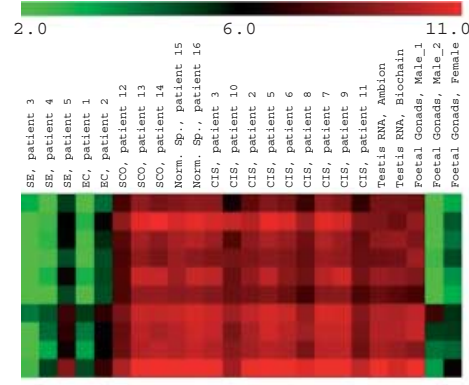

Testis microRNA cluster

(b)

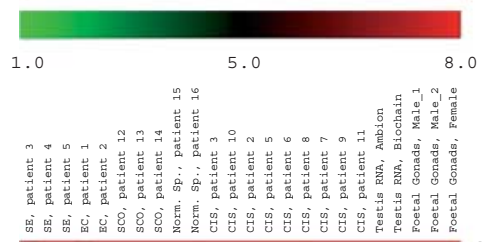

hsa-miR-506 hsa-miR -507 hsa-miR $-508-3 p$ hsa-miR-509-3p hsa-miR-510 hsa-miR-510 hsa-miR-513b hsa-miR-513c hsa-miR-514

(d)

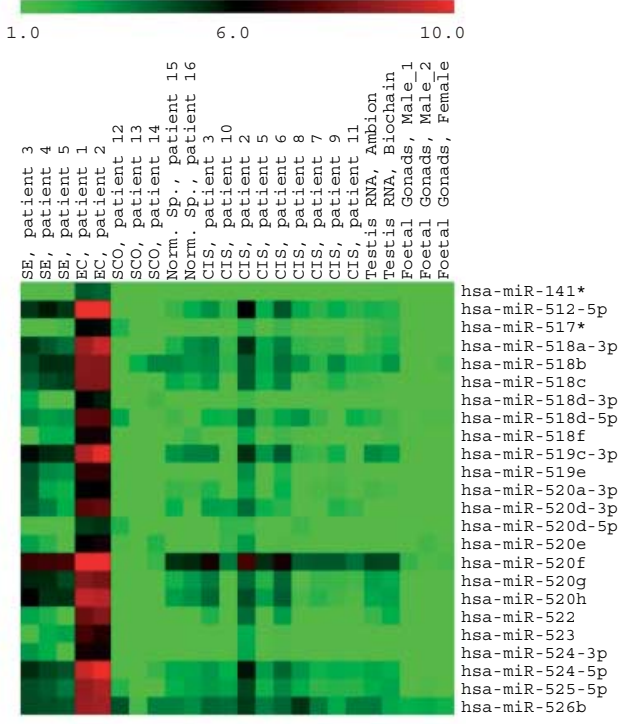

Up in embryonal carcinoma

(e)

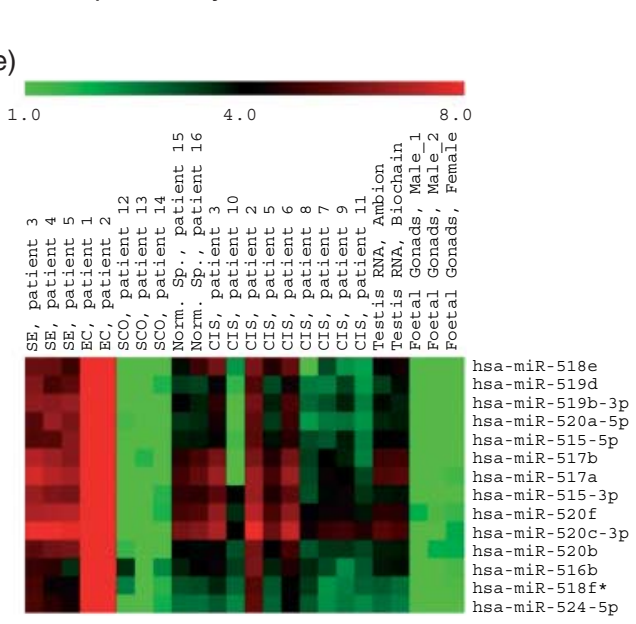

Up in CIS vs foetal gonads

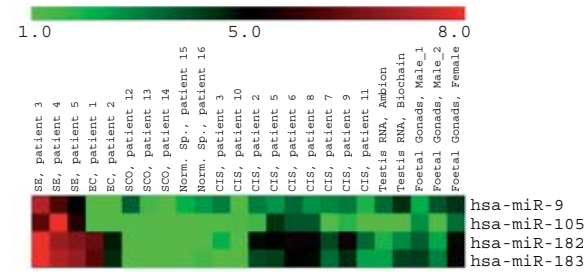

Up in seminoma hsa-miR-130 hsa-miR-101 hsa-miR-377 hsa-miR-376a hsa-miR-557 hsa-miR-572 hsa-miR-663 hsa-miR-154 hsa-miR-193a-3 hsa-miR-495 hsa-miR-487b hsa-miR-299-5b hsa-miR-146b-5p hsa-miR-146a hsa-miR-154 * hsa-miR-96. hsa-miR-302a hsa-miR-367 hsa-miR-371-3p hsa-miR -372 hsa-miR-200c hsa-miR-183 hsa-miR-182 hsa-miR-302C hsa-miR-302a* hsa-miR-302 hsa-miR-526b hsa-miR-124 hsa-miR-43i hsa-miR -433 hsa-miR-373 hsa-miR-629 hsa-mir hsa-miR-54 hsa-miR -563 kshv-miR-K12-1 hsa-miR-769-3p hsa-miR- 640 hsa-miR-596 hsa-miR-767-5p hsa-miR-105 hsa-miR-323-3p

(c)

(4)

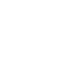

MicroRNAs correlating with CIS cell content

Figure 2 miRNAs differentially expressed between the samples. (a) Cluster of testis-specific miRNAs. (b) Heat map of miRNAs correlating with $\mathrm{CIS}$ cell content with $R>0.8$ as well as hsa-miR-323-3p (Supplementary Table 1, see section on supplementary data given at the end of this article). (c) miRNAs upregulated in SE. (d) miRNAs upregulated in ECs. (e) miRNAs upregulated in the CIS samples compared with foetal gonads, selected from a two-way SAM analysis (CIS samples vs foetal gonads, $\delta 0.588$; FDR $0.0 \%$ ). 
(a)
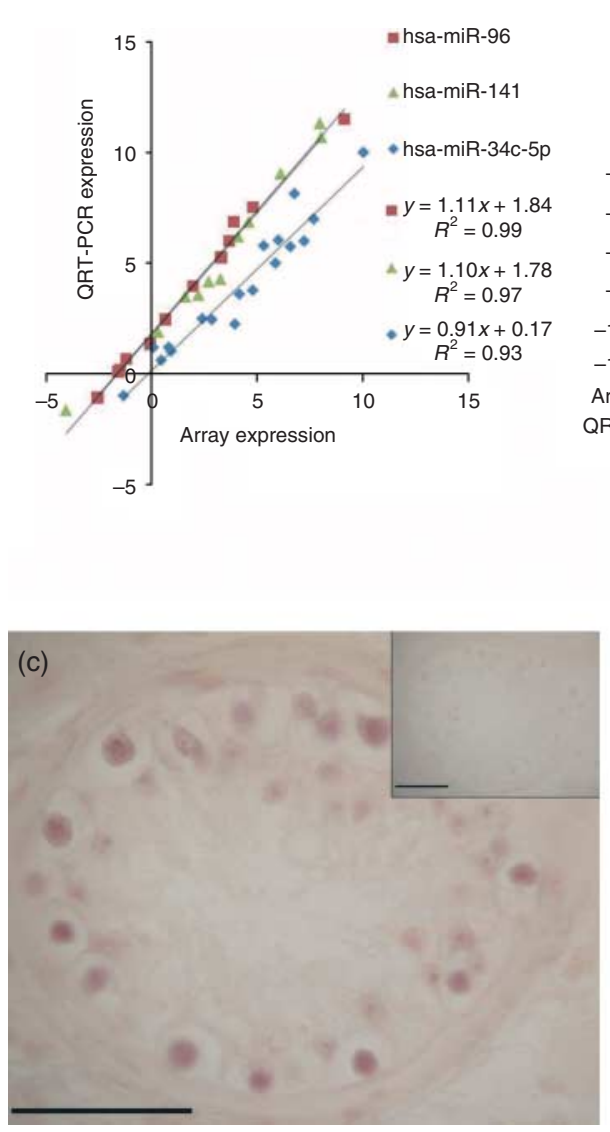

(b) $\log _{2}$ hsa-miR-3p expression relative to hsa-miR-103
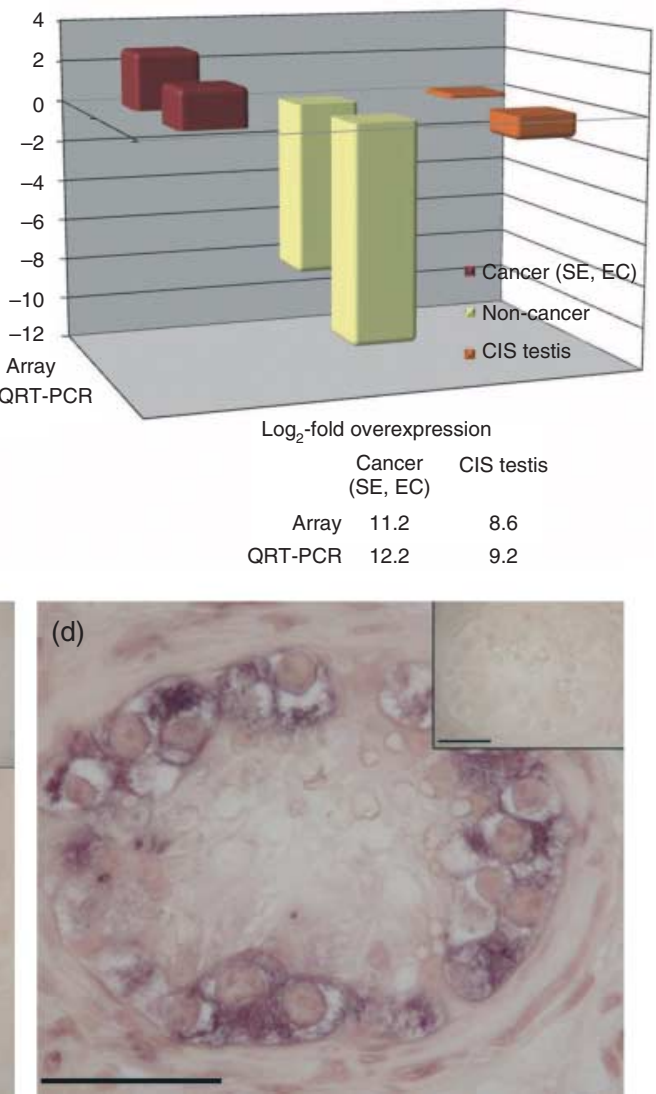

Figure 3 Verification of the microarray results. (a) qRT-PCR verification of microarray expression. Log 2 miRNA qRT-PCR expression values (normalised to hsa-miR-103) from the tissue samples were plotted against $\log _{2}$ miRNA array expression values (normalised to hsa-miR-103) from the same samples. hsa-miR-96, -141 and -34c-5p are shown here. (b) qRT-PCR validation of microarray-detected fold changes of hsa-miR-371-3p (normalised to hsa-miR-103) between cancers, non-cancers and testis with CIS. $\log _{2}$ expression values from microarrays and qRT-PCR from the same samples are plotted next to each other for cancers (red, $n=5$, STDEV 0.7 for microarray data, 2.12 for qRT-PCR data), non-cancers (yellow, $n=4$, STDEV 0.84 for array data, 2.42 for qRT-PCR data) and CIS testis (orange, $n=3$, STDEV 1.37 for array data, 0.61 for qRT-PCR data). The calculated log ${ }_{2}$-fold overexpression of hsa-miR-371-3p in cancers and CIS testis compared with non-cancers is shown below the plot. (c) In situ hybridisation with an anti-sense probe for the pri-hsa-miR-96 transcript on a biopsy from testis with CIS. Expression of the pri-hsa-miR-96 transcript was detected in the nucleus of CIS cells, while the sense control RNA showed no staining (insert image). (d) In situ hybridisation with a sense probe against the pri-hsa-miR-371-373 cluster; the insert shows hybridisation with an anti-sense probe. No expression of the primary transcript (anti-sense probe) could be detected, presumably due to fast processing of the transcript, while there was a high expression from the opposite strand (sense probe). Scale bars correspond to $50 \mu \mathrm{M}$.

\section{Investigating biological function of miRNA expression}

miRNA targets are often degraded or deadenylated (Bagga et al. 2005, Eulalio et al. 2009) and can therefore be discovered by mRNA profiling. Thus, we selected 16 miRNAs deregulated in the CIS samples and testis tumours (miRNAs in Table 2 and hsa-miR141, -182, -200c and -323-3p; Fig. 2b and Supplementary Table 1 , see section on supplementary data given at the end of this article) for target prediction. We were able to predict a total of 607 targets for 13 out of the 16 miRNAs using the database miRecords (http:// mirecords.biolead.org/). Using mRNA array data from specific microdissected testicular cell types (Sonne et al. 2009a), we then calculated the fold change in the expression of these mRNAs between the CIS cells and normal testis. To avoid noise, the calculations were performed after filtering out genes with fold changes between -0.5 and +0.5 . After this filtering, we found 5237 up- and 3905 downregulated genes in the full dataset of genes, while the miRNA targets showed 118 up- and 150 downregulated genes (Supplementary 
Table 2, see section on supplementary data given at the end of this article), which is a significant enrichment of downregulated genes (expected values: 154 up and 114 down, $\left.P<0.0001, \chi^{2}=19.244, \mathrm{df}=1\right)$.

Assuming we could detect the influence of the miRNAs on the mRNA level of all their targets, we determined the expression changes (CIS cells vs normal testis) of all miRNA target mRNAs $(n=596)$ as a group compared with the rest of the annotated transcripts on the array $(n=16431)$, and we compared the two groups in each test by a Wilcoxon-MannWhitney test. To get an estimate of any multiple testing biases, we performed 1000 random Wilcoxon-MannWhitney tests and only trusted the Wilcoxon-MannWhitney $P$ value if maximum one random test had a lower $P$ value than the correct test. The expression of the miRNA-targeted mRNAs was significantly changed compared with the background $\left(P=1.63 \times 10^{-8}\right)$. To identify whether some of the miRNAs seemed to influence their targets more than the others, we tested the miRNA target groups individually. The expression of two miRNA target groups, hsa-miR-141 $(P=0.0037)$ and hsa-miR-200c $(P=0.0003)$, was significantly changed compared with the background and hence could play a role in maintaining the CIS phenotype.

We further investigated the role of the potential miRNA targets of hsa-miRNA-141 and -200 c by enrichment analyses. We used the enrichment tool at the Panther website (http://www.pantherdb.org/) to assign the mRNA targets of these miRNAs (84 targets for hsa-miR-141 and 157 targets for hsa-miR-200c; Supplementary Table 2, see section on supplementary data given at the end of this article) to Gene Ontology categories. The predicted targets of hsa-miR-141 were enriched in the biological processes: establishment or maintenance of chromatin architecture, organelle organisation and anterior/posterior axis specification and the molecular function deacetylase activity. The predicted hsa-miR-200c targets were enriched in the biological processes, including endoderm development, apoptosis, signal transduction and intracellular signalling cascade, and in the molecular functions, such as transcription factor activity, transcription regulator activity, transcription cofactor activity and DNA binding.

\section{Discussion}

In this study, we have for the first time examined global miRNA expression in CIS cells, the precursor cell for testicular germ cell cancer. Since CIS cells only constitute a small percentage of the cells in the testis, we identified miRNAs that were expressed in CIS cells by identifying miRNAs whose expression correlated with the ratio of tubules with CIS cells. However, this may lead to an overestimation of the expression of miRNAs that are uniquely expressed in CIS cells when compared with miRNAs that also are expressed in other testis cell types (Sonne et al. 2009a). Nevertheless, this calculation probably identifies most miRNAs that are expressed in CIS cells (Table 2 and Supplementary Table 1, see section on supplementary data given at the end of this article).

The results show a strong correlation between miRNA expression in CIS cells and gonocytes, which is in accordance with the similar mRNA expression profiles (Sonne et al. 2009a). Especially, two miRNA clusters (hsa-miR-371-373 and -302-367), which have been reported to be highly expressed exclusively in ESC (Martinez \& Gregory 2010) and in testicular (Gillis et al. 2007) and extragonadal paediatric germ cell tumours (Murray et al. 2010, Palmer et al. 2010), were also expressed in CIS cells and foetal gonads. This supports our hypothesis that CIS cells are arrested gonocytes that persist in the adult testis instead of differentiating into spermatogonia or entering apoptosis around birth (Sonne et al. 2009a). Nevertheless, we also identified a number of miRNAs that were differentially expressed between CIS cells and foetal gonads (Fig. 2e), indicating that the developmental arrest of gonocytes that lead to CIS cells may be enforced by miRNAs. The data confirmed a high expression of the hsa-miR-9, -105 and -182-183-96 clusters in SEs and the hsa-miR-515-526 cluster in ECs as previously suggested by Palmer et al. (2010). Although the highest expression appears to be in the tumours, we also observed a moderate expression of these miRNAs in the testes with CIS cells adjacent to EC or SE as well as in the normal control testis. Notably, the hsa-miR-515-526 cluster was not expressed in the SCO samples and foetal gonocytes, but their presence in the normal testicular samples and CIS cells suggested that the cluster is induced by the signals that initiate spermatogenesis and that it may have a function in germ cells and maybe during the transformation of CIS cells to overt tumours. However, in CIS cells, the expression of the clusters that are differentially expressed in SE and EC does not seem to be predictive of the tumour type adjacent to the CIS cells. There are large phenotypic differences between SE and NS, and also among several histological subtypes of the latter (Juric et al. 2005, Korkola et al. 2005, Skotheim et al. 2005). Given a desire to find early markers predictive of invasive progression either to SE or to the more clinically aggressive NS, 
discussion concerning possible differences between the CIS cells adjacent to the two respective tumour types has been circulating in the literature (reviewed recently by Alagaratnam et al. (2011)). However, only very subtle differences in gene expression between CIS/SE and CIS/NS have been reported (Almstrup et al. 2005, Skotheim et al. 2005) and those have not been found recurrent in an in silico analysis of a larger number of samples (Almstrup et al. 2007). Accordingly, we have not identified miRNA clusters specific for CIS/SE or CIS/NS in the present study. This makes sense from a biological point of view: first, SE and NS quite frequently (up to $30 \%$ of all TGCT cases) occur in the same testicle, often intimately mixed together in a combined tumour (Ulbright et al. 1999), and secondly, the CIS cells adjacent to a tumour are not the precursors of this tumour, but more 'dormant' cells, which did not achieve invasiveness. Thirdly, general heterogeneity and plasticity is a feature of the CIS phenotype (Rajpert-De Meyts et al. 1996, Gueler et al. 2012), thus a SE- or NS-specific CIS type cannot be identified in the available tissue samples or most probably, it does not exist.

Our bioinformatic results showed an enrichment of downregulated miRNA target genes in testis with CIS, and when assigning functions to the most downregulated mRNAs, we found tumour suppressors (PCDH9, PDS5B, ETS2 and MTCH2; Yu et al. 2008, Denes et al. 2010, Múnera et al. 2011, Wang et al. 2012; Supplementary Table 2, see section on supplementary data given at the end of this article), indicative of the cancer potential of the CIS cells. Interestingly, some oncogenes (RAP2C and WHSCl) are also among the most downregulated miRNA targets; however, experiments in cancer cell lines where WHSCl expression was knocked down resulted in the suppression of proliferation (Toyokawa et al. 2011), which fits with the phenotype of the CIS cells as a quiescent cancer precursor cell. The enrichment of downregulated miRNA targets observed in our data supports the view that most miRNA targets are deadenylated and eventually degraded (Bagga et al. 2005, Behm-Ansmant et al. 2006, Eulalio et al. 2009), thus allowing the detection of potential targets by combining miRNA and mRNA expression data (Tzur et al. 2009, Palmer et al. 2010, Zibert et al. 2010). Our analysis of miRNA and mRNA expression data from the normal testis and testis with CIS suggested that hsamir-141 and -200c, which are not expressed in the normal testis (Fig. 2b), might be important for CIS cell biology. Interestingly, these two miRNAs are also upregulated in human ovarian cancer (Iorio et al. 2007). From the enrichment analysis of the predicted targets of hsa-miR-141, we found that the targets were involved in many differentiation and developmental processes. The enrichment fits the hypothesis that CIS cells are developmentally arrested gonocytes and indicated that hsa-miR-141 targets could be involved in the development of CIS cells and/or the retention of the arrested state. The predicted targets of hsa-miR200c were enriched in endoderm development, which also agrees with the developmental arrest. The hsamiR-200c targets were further enriched in several categories of transcription and transcription co-factor activity. Among the transcription cofactors targeted by hsa-miR-200c is $\mathrm{Cbp} / \mathrm{p} 300$-interacting transactivator, with Glu/Asp-rich carboxy-terminal domain, 2 (Cited2), which is important in testis development (Combes et al. 2010).

The expression profiles confirmed the high expression of the embryonic and oncogenic hsa-miR17-92 cluster (Thomson et al. 2004, Mineno et al. 2006, Calabrese et al. 2007) in testis (Fig. 1c; Novotny et al. 2007b) and showed that the cluster already is expressed in foetal gonads of both sexes. The expression of the hsa-miR-17-92 cluster is regulated by MYC and several of the encoded miRNAs repress the expression of the transcription factor E2F1 (Olive et al. 2010). Thus, despite the abundant presence of the E2F1 transcript in meiotic germ cells and CIS cells (Almstrup et al. 2004), the hsa-miR-17-92 cluster prevents expression of the E2F1 protein in CIS cells and in specific germ cell types during meiosis in normal testis (Novotny et al. 2007b). However, a survey of the E2F1 expression in 34 testis tumours revealed a moderate to strong E2F1 protein staining in 18-20 of the tumours (proteinatlas.org), which is surprising since testis tumours are derived from CIS cells. A potential explanation may come from a recent investigation of copy number variation in testicular SE reporting that the hsa-miR-17-92 cluster on chromosome 13q31.3 (overlap with GPC5) is deleted in 20$25 \%$ of the SE specimens (Lebron et al. 2011), which may indicate that regain of E2F1 expression in the absence of the hsa-miR-17-92 cluster may lead to the formation of some testis tumours.

The detection of miRNAs that in the testis are expressed exclusively in CIS cells and germ cell tumours may have clinical implications since the expression of developmentally regulated genes such as TFAP2C $(A P 2 \gamma)$ and POU5F1 (OCT3/4) in CIS cells and germ cell tumours, but not in normal adult testis, has been exploited for screening of semen samples for preinvasive testicular cancer (Hoei-Hansen et al. 2007, van Casteren et al. 2008). Thus, the very restricted expression of the hsa-miR-371-373 and -302-367 
clusters in CIS cells and germ cell tumours may open for a PCR-based screening of serum samples for testis cancer (Murray et al. 2011).

In conclusion, we have detected several miRNA clusters that are differentially expressed during human testis development and germ cell malignancy. The expression of miRNA clusters in CIS cells that normally only are found in foetal cells supports our long-standing hypothesis that testis cancer is an adult manifestation of a developmental problem of foetal germ cells. These miRNAs are probably involved in the modulation of the unique phenotype of both foetal gonocytes and CIS cells and may have biological and clinical implications.

\section{Supplementary data}

This is linked to the online version of the paper at http://dx. doi.org/10.1677/ERC-11-0271.

\section{Declaration of interest}

The authors declare that there is no conflict of interest that could be perceived as prejudicing the impartiality of the research reported.

\section{Funding}

This work was supported by grants from the Villum Kann Rasmussen Foundation and the Danish Cancer Society.

\section{Author contribution statement}

G W Novotny made the RNA preparations and the miRNA microarrays and helped with the manuscript; K C Belling made the miRNA target predictions, the gene enrichment analysis and analysis of the microdissected gene expression data and helped with the manuscript; J B Bramsen made the qPCR validation; J E Nielsen made the ISH and AMH immunohistochemistry; J Bork-Jensen helped with the analysis of the miRNA microarrays; $\mathrm{K}$ Almstrup helped with the normalisation of miRNA microarrays and with the manuscript; S B Sonne made the mRNA microarrays; E Rajpert-De Meyts helped with sample selection and the manuscript; J Kjems helped with the manuscript; and $\mathrm{H}$ Leffers designed the study and was responsible for preparing the manuscript.

\section{Acknowledgements}

The authors thank Sabina Soultanova and Brian Vendelbo Hansen for their excellent technical assistance and Drs Ludmila Ruban and Harry Moore for providing the foetal gonads.

\section{References}

Alagaratnam S, Lind GE, Kraggerud SM, Lothe RA \& Skotheim RI 2011 The testicular germ cell tumour transcriptome. International Journal of Andrology 34 (4 Pt 2) e133-e150. (doi:10.1111/j.1365-2605.2011. 01169.x)

Almstrup K, Hoei-Hansen CE, Wirkner U, Blake J, Schwager C, Ansorge W, Nielsen JE, Skakkebaek NE, Rajpert-De Meyts E \& Leffers H 2004 Embryonic stem cell-like features of testicular carcinoma in situ revealed by genome-wide gene expression profiling. Cancer Research 64 4736-4743. (doi:10.1158/00085472.CAN-04-0679)

Almstrup K, Hoei-Hansen CE, Nielsen JE, Wirkner U, Ansorge W, Skakkebæk NE, Rajpert-De Meyts E \& Leffers $\mathrm{H} 2005$ Genome-wide gene expression profiling of testicular carcinoma in situ progression into overt germ cell tumours. British Journal of Cancer 92 1934-1941. (doi:10.1038/sj.bjc.6602560)

Almstrup K, Leffers H, Lothe RA, Skakkebæk NE, Sonne SB, Nielsen JE, Rajpert-De Meyts E \& Skotheim R 2007 Improved gene expression signature of testicular carcinoma in situ. International Journal of Andrology 30 293-303. (doi:10.1111/j.1365-2605.2007.00758.x)

Bagga S, Bracht J, Hunter S, Massirer K, Holtz J, Eachus R \& Pasquinelli AE 2005 Regulation by let-7 and lin-4 miRNAs results in target mRNA degradation. Cell $\mathbf{1 2 2}$ 553-563. (doi:10.1016/j.cell.2005.07.031)

Bartel DP 2004 MicroRNAs: genomics, biogenesis, mechanism, and function. Cell 116 281-297. (doi:10.1016/S0092-8674(04)00045-5)

Behm-Ansmant I, Rehwinkel J, Doerks T, Stark A, Bork P \& Izaurralde E 2006 mRNA degradation by miRNAs and GW182 requires both CCR4:NOT deadenylase and DCP1:DCP2 decapping complexes. Genes and Development 20 1885-1898. (doi:10.1101/gad.1424106)

Bentwich I, Avniel A, Karov Y, Aharonov R, Gilad S, Barad O, Barzilai A, Einat P, Einav U, Meiri E et al. 2005 Identification of hundreds of conserved and nonconserved human microRNAs. Nature Genetics 37 766-770. (doi:10.1038/ng1590)

Calabrese JM, Seila AC, Yeo GW \& Sharp PA 2007 RNA sequence analysis defines Dicer's role in mouse embryonic stem cells. PNAS 104 18097-18102. (doi:10.1073/pnas.0709193104)

van Casteren NJ, Stoop H, Dohle GR, de Wit R, Oosterhuis JW \& Looijenga LH 2008 Noninvasive detection of testicular carcinoma in situ in semen using OCT3/4. European Urology 54 153-158. (doi:10.1016/j.eururo. 2007.10.042)

Cho WC 2007 OncomiRs: the discovery and progress of microRNAs in cancers. Molecular Cancer 660. (doi:10.1186/1476-4598-6-60)

Combes AN, Spiller CM, Harley VR, Sinclair AH, Dunwoodie SL, Wilhelm D \& Koopman P 2010 Gonadal defects in Cited2-mutant mice indicate a role for SF1 in 
both testis and ovary differentiation. International Journal of Developmental Biology 54 683-689. (doi:10.1387/ijdb.092920ac)

Denes V, Pilichowska M, Makarovskiy A, Carpinito G \& Geck P 2010 Loss of a cohesin-linked suppressor APRIN (Pds5b) disrupts stem cell programs in embryonal carcinoma: an emerging cohesin role in tumor suppression. Oncogene 29 3446-3452. (doi:10.1038/onc. 2010.100)

Esquela-Kerscher A \& Slack FJ 2006 Oncomirs - microRNAs with a role in cancer. Nature Reviews. Cancer 6 259-269. (doi:10.1038/nrc1840)

Eulalio A, Huntzinger E, Nishihara T, Rehwinkel J, Fauser M \& Izaurralde E 2009 Deadenylation is a widespread effect of miRNA regulation. RNA 15 21-32. (doi:10.1261/rna. 1399509)

Feldman DR, Bosl GJ, Sheinfeld J \& Motzer RJ 2008 Medical treatment of advanced testicular cancer. JAMA 299 672-684. (doi:10.1001/jama.299.6.672)

Gillis AJ, Stoop HJ, Hersmus R, Oosterhuis JW, Sun Y, Chen C, Guenther S, Sherlock J, Veltman I, Baeten J et al. 2007 High-throughput microRNAome analysis in human germ cell tumours. Journal of Pathology 213 319-328. (doi:10.1002/path.2230)

Giwercman A, Cantell L \& Marks A 1991 Placental-like alkaline phosphatase as a marker of carcinoma-in-situ of the testis. Comparison with monoclonal antibodies M2A and 43-9F. APMIS 99 586-594. (doi:10.1111/j.16990463.1991.tb01231.x)

Gueler B, Sonne SB, Zimmer J, Hilscher B, Hilscher W, Graem N, Rajpert-De Meyts E \& Vogt PH 2012 AZFa protein DDX3Y is differentially expressed in male germ cells during development and in testicular tumours: new evidence for phenotypic plasticity of germ cells. Human Reproduction [in press]. (doi:10.1093/humrep/des047)

He L, Thomson JM, Hemann MT, Hernando-Monge E, Mu D, Goodson S, Powers S, Cordon-Cardo C, Lowe SW, Hannon GJ et al. 2005 A microRNA polycistron as a potential human oncogene. Nature 435 828-833. (doi:10.1038/nature03552)

Hoei-Hansen CE, Carlsen E, Jorgensen N, Leffers H, Skakkebaek NE \& Rajpert-De Meyts E 2007 Towards a non-invasive method for early detection of testicular neoplasia in semen samples by identification of fetal germ cell-specific markers. Human Reproduction 22 167-173. (doi:10.1093/humrep/del320)

Holstein AF \& Korner F 1974 Light and electron microscopical analysis of cell types in human seminoma. Virchows Archiv. A, Pathological Anatomy and Histopathology 363 97-112. (doi:10.1007/BF01201313)

Iorio MV, Visone R, Di Leva G, Donati V, Petrocca F, Casalini P, Taccioli C, Volinia S, Liu CG, Alder H et al. 2007 MicroRNA signatures in human ovarian cancer. Cancer Research 67 8699-8707. (doi:10.1158/00085472.CAN-07-1936)

Juric D, Sale S, Hromas RA, Yu R, Wang Y, Duran GE, Tibshirani R, Einhorn LH \& Sikic BI 2005 Gene expression profiling differentiates germ cell tumors from other cancers and defines subtype-specific signatures. PNAS 102 17763-17768. (doi:10.1073/pnas.0509082102)

Korkola JE, Houldsworth J, Dobrzynski D, Olshen AB, Reuter VE, Bosl GJ \& Chaganti RS 2005 Gene expression-based classification of nonseminomatous male germ cell tumors. Oncogene 24 5101-5107. (doi:10.1038/ sj.onc.1208694)

Lai EC 2002 Micro RNAs are complementary to $3^{\prime}$ UTR sequence motifs that mediate negative post-transcriptional regulation. Nature Genetics 30 363-364. (doi:10.1038/ng865)

Landgraf P, Rusu M, Sheridan R, Sewer A, Iovino N, Aravin A, Pfeffer S, Rice A, Kamphorst AO, Landthaler M et al. 2007 A mammalian microRNA expression atlas based on small RNA library sequencing. Cell 129 1401-1414. (doi:10.1016/j.cell.2007.04.040)

Lebron C, Pal P, Brait M, Dasgupta S, Guerrero-Preston R, Looijenga LH, Kowalski J, Netto G \& Hoque MO 2011 Genome-wide analysis of genetic alterations in testicular primary seminoma using high resolution single nucleotide polymorphism arrays. Genomics 97 341-349. (doi:10.1016/j.ygeno.2011.02.011)

Looijenga LH, Gillis AJ, Stoop HJ, Hersmus R \& Oosterhuis JW 2007 Chromosomes and expression in human testicular germ-cell tumors: insight into their cell of origin and pathogenesis. Annals of the New York Academy of Sciences 1120 187-214. (doi:10.1196/annals. 1411.000)

Martinez NJ \& Gregory RI 2010 MicroRNA gene regulatory pathways in the establishment and maintenance of ESC identity. Cell Stem Cell 7 31-35. (doi:10.1016/j.stem. 2010.06.011)

Mineno J, Okamoto S, Ando T, Sato M, Chono H, Izu H, Takayama M, Asada K, Mirochnitchenko O, Inouye M et al. 2006 The expression profile of microRNAs in mouse embryos. Nucleic Acids Research 34 1765-1771. (doi:10.1093/nar/gk1096)

Múnera J, Ceceña G, Jedlicka P, Wankell M \& Oshima RG 2011 Ets 2 regulates colonic stem cells and sensitivity to tumorigenesis. Stem Cells 29 430-439. (doi:10.1002/ stem.599)

Murray MJ, Saini HK, van Dongen S, Palmer RD, Muralidhar B, Pett MR, Piipari M, Thornton CM, Nicholson JC, Enright AJ et al. 2010 The two most common histological subtypes of malignant germ cell tumour are distinguished by global microRNA profiles, associated with differential transcription factor expression. Molecular Cancer 9 290. (doi:10.1186/14764598-9-290)

Murray MJ, Halsall DJ, Hook CE, Williams DM, Nicholson JC \& Coleman N 2011 Identification of microRNAs From the miR-371-373 and miR-302 clusters as potential serum biomarkers of malignant germ cell tumors. American Journal of Clinical Pathology 135 119-125. (doi:10.1309/AJCPOE11 KEYZCJHT) 
Nielsen JE, Hansen MA, Jorgensen M, Tanaka M, Almstrup K, Skakkebaek NE \& Leffers H 2003 Germ cell differentiation-dependent and stage-specific expression of LANCL1 in rodent testis. European Journal of Histochemistry 47 215-222.

Novotny GW, Sonne SB, Nielsen JE, Jonstrup SP, Hansen MA, Skakkebaek NE, Rajpert-De Meyts E, Kjems J \& Leffers H 2007a Translational repression of E2F1 mRNA in carcinoma in situ and normal testis correlates with expression of the miR-17-92 cluster. Cell Death and Differentiation 14 879-882. (doi:10.1038/sj. cdd.4402090)

Novotny GW, Nielsen JE, Sonne SB, Skakkebaek NE, Rajpert-De Meyts E \& Leffers H 2007b Analysis of gene expression in normal and neoplastic human testis: new roles of RNA. International Journal of Andrology 30 316-326. (doi:10.1111/j.1365-2605.2007.00773.x)

O’Donnell KA, Wentzel EA, Zeller KI, Dang CV \& Mendell JT 2005 c-Myc-regulated microRNAs modulate E2F1 expression. Nature 435 839-843. (doi:10.1038/ nature03677)

Olive V, Jiang I \& He L 2010 mir-17-92, a cluster of miRNAs in the midst of the cancer network. International Journal of Biochemistry \& Cell Biology 42 1348-1354. (doi:10.1016/j.biocel.2010.03.004)

Orom UA, Nielsen FC \& Lund AH 2008 MicroRNA-10a binds the $5^{\prime} \mathrm{UTR}$ of ribosomal protein mRNAs and enhances their translation. Molecular Cell 30 460-471. (doi:10.1016/j.molcel.2008.05.001)

Palmer RD, Murray MJ, Saini HK, van Dongen S, Abreu-Goodger C, Muralidhar B, Pett MR, Thornton CM, Nicholson JC, Enright AJ et al. 2010 Malignant germ cell tumors display common microRNA profiles resulting in global changes in expression of messenger RNA targets. Cancer Research 70 2911-2923. (doi:10.1158/00085472.CAN-09-3301)

Rajpert-De Meyts E, Kvist M \& Skakkebæk NE 1996 Heterogeneity of expression of immunohistochemical tumour markers in the testicular carcinoma in situ: pathogenetic relevance. Virchows Archiv: an International Journal of Pathology 428 133-139. (doi:10. 1007/BF00200655)

Ro S, Park C, Sanders KM, McCarrey JR \& Yan W 2007 Cloning and expression profiling of testis-expressed microRNAs. Developmental Biology 311 592-602. (doi:10.1016/j.ydbio.2007.09.009)

Saeed AI, Sharov V, White J, Li J, Liang W, Bhagabati N, Braisted J, Klapa M, Currier T, Thiagarajan M, Sturn A et al. 2003 TM4: a free, open-source system for microarray data management and analysis. Biotechniques 34 374-378.

Sarver AL, Li L \& Subramanian S 2010 MicroRNA miR-183 functions as an oncogene by targeting the transcription factor EGR1 and promoting tumor cell migration. Cancer Research 70 9570-9580. (doi:10.1158/0008-5472.CAN10-2074)
Schmoll HJ, Souchon R, Krege S, Albers P, Beyer J, Kollmannsberger C, Fossa SD, Skakkebaek NE, de Wit R, Fizazi K et al. 2004 European consensus on diagnosis and treatment of germ cell cancer: a report of the European Germ Cell Cancer Consensus Group (EGCCCG). Annals of Oncology 15 1377-1399. (doi:10.1093/annonc/ mdh301)

Skakkebaek NE, Berthelsen JG, Giwercman A \& Muller J 1987 Carcinoma-in-situ of the testis: possible origin from gonocytes and precursor of all types of germ cell tumours except spermatocytoma. International Journal of Andrology 10 19-28. (doi:10.1111/j.1365-2605.1987.tb00161.x)

Skotheim RI, Lind GE, Monni O, Nesland JM, Abeler VM, Fosså SD, Duale N, Brunborg G, Kallioniemi O, Andrews PW et al. 2005 Differentiation of human embryonal carcinomas in vitro and in vivo reveals expression profiles relevant to normal development. Cancer Research $\mathbf{6 5}$ 5588-5598. (doi:10.1158/0008-5472.CAN-05-0153)

Sonne SB, Almstrup K, Dalgaard M, Juncker AS, Edsgard D, Ruban L, Harrison NJ, Schwager C, Abdollahi A, Huber PE et al. 2009a Analysis of gene expression profiles of microdissected cell populations indicates that testicular carcinoma in situ is an arrested gonocyte. Cancer Research 69 5241-5250. (doi:10.1158/0008-5472.CAN08-4554)

Sonne SB, Dalgaard MD, Nielsen JE, Hoei-Hansen CE, Rajpert-De Meyts E, Gjerdrum LM \& Leffers H $2009 b$ Optimizing staining protocols for laser microdissection of specific cell types from the testis including carcinoma in situ. PLoS ONE 4 e5536. (doi:10.1371/journal.pone. 0005536)

Thomson JM, Parker J, Perou CM \& Hammond SM 2004 A custom microarray platform for analysis of microRNA gene expression. Nature Methods 1 47-53. (doi:10.1038/ nmeth704)

Toyokawa G, Cho HS, Masuda K, Yamane Y, Yoshimatsu M, Hayami S, Takawa M, Iwai Y, Daigo Y, Tsuchiya E et al. 2011 Histone lysine methyltransferase Wolf-Hirschhorn syndrome candidate 1 is involved in human carcinogenesis through regulation of the Wnt pathway. Neoplasia 13 887-898. (doi: 10.1593/neo.11048)

Tzur G, Israel A, Levy A, Benjamin H, Meiri E, Shufaro Y, Meir K, Khvalevsky E, Spector Y, Rojansky N et al. 2009 Comprehensive gene and microRNA expression profiling reveals a role for microRNAs in human liver development. PLoS ONE 4 e7511. (doi:10.1371/journal.pone. 0007511)

Ulbright TM, Amin MB \& Young RH 1999 Tumors of the testis, adnexa, spermatic cord, and scrotum. In Atlas of Tumor Pathology, third series, fascicle 35, pp 1-373. Eds J Rosai, LH Sobin. Bethesda, MD, USA: Armed Forces Institute of Pathology.

Voorhoeve PM, le Sage C, Schrier M, Gillis AJ, Stoop H, Nagel R, Liu YP, van Duijse J, Drost J, Griekspoor A et al. 2006 A genetic screen implicates miRNA-372 and miRNA-373 as oncogenes in testicular germ cell tumors. Cell 124 1169-1181. (doi:10.1016/j.cell.2006.02.037) 
Wang C, Yu G, Liu J, Wang J, Zhang Y, Zhang X, Zhou Z \& Huang Z 2012 Downregulation of PCDH9 predicts prognosis for patients with glioma. Journal of Clinical Neuroscience 19 541-545. (doi: 10.1016/j.jocn.2011. 04.047)

Wilson KD, Venkatasubrahmanyam S, Jia F, Sun N, Butte AJ \& Wu JC 2009 MicroRNA profiling of human-induced pluripotent stem cells. Stem Cells and Development 18 749-758. (doi:10.1089/scd.2008.0247)

Winter C \& Albers P 2011 Testicular germ cell tumors: pathogenesis, diagnosis and treatment. Nature Reviews. Endocrinology 7 43-53. (doi:10.1038/nrendo.2010.196)

Xie X, Lu J, Kulbokas EJ, Golub TR, Mootha V, Lindblad-Toh K, Lander ES \& Kellis M 2005 Systematic discovery of regulatory motifs in human promoters and $3^{\prime}$ UTRs by comparison of several mammals. Nature 434 338-345. (doi:10.1038/nature03441)

Yamada Y, Enokida H, Kojima S, Kawakami K, Chiyomaru T, Tatarano S, Yoshino H, Kawahara K, Nishiyama K, Seki N et al. 2011 MiR-96 and miR-183 detection in urine serve as potential tumor markers of urothelial carcinoma: correlation with stage and grade, and comparison with urinary cytology. Cancer Science $\mathbf{1 0 2}$ 522-529. (doi:10.1111/j.1349-7006.2010.01816.x)

Yu K, Ganesan K, Tan LK, Laban M, Wu J, Zhao XD, Li H, Leung CH, Zhu Y, Wei CL et al. 2008 A precisely regulated gene expression cassette potently modulates metastasis and survival in multiple solid cancers. PLoS Genetics 4 e1000129. (doi:10.1371/journal.pgen.1000129)

Zibert JR, Lovendorf MB, Litman T, Olsen J, Kaczkowski B \& Skov L 2010 MicroRNAs and potential target interactions in psoriasis. Journal of Dermatological Science $\mathbf{5 8}$ 177-185. (doi:10.1016/j.jdermsci.2010.03.004)

Received in final form 13 March 2012

Accepted 14 March 2012

Made available online as an Accepted Preprint 14 March 2012 